\title{
O Plano Municipal de Educação de Curitiba no aspecto da educação inclusiva: contribuições para diagnóstico e perspectivas
}

\section{Curitiba Education Plan in the aspect of inclusive education: contributions to diagnosis and perspectives}

\author{
Raphael Demóstenes Cardozo ${ }^{1}$ \\ Gabriela Schneider ${ }^{2}$
}

\section{Resumo}

O presente trabalho objetiva analisar o Plano Municipal de Educação de Curitiba (PME) a partir de indicadores construídos com os dados do Censo escolar, no que tange especificamente, a meta relativa ao público-alvo da educação especial (PAEE). Há consonância aos pressupostos da Política Nacional de Educação Especial na perspectiva da educação inclusiva. A proposição de análise quantitativa se centra nos dados de matrícula, no Atendimento Educacional Especializado (AEE) e nas condições de oferta, entendendo que a universalização do acesso precisa ser feita com condições de qualidade. A análise sugere uma diminuição do atendimento educacional especializado em instituições conveniadas, o que sinaliza uma postura diferente do que se observa no país. Curitiba, tem realizado o AEE em instituições próprias, nas próprias escolas ou em Centros Municipais de Atendimento Educacional Especializado (CMAEE).

Palavras-chaves: Plano Municipal de Educação; Educação Especial; Indicadores educacionais;

\begin{abstract}
The present work aims to analyze the Municipal Education Plan of Curitiba (PME) from indicators built with data from the School Census, specifically with regard specifically for the target public of special education (PAEE). There is consonance with the assumptions of the National Special Education Policy from the perspective of inclusive education. The proposition of quantitative analysis is centered on enrollment data, on Specialized Educational Attendance (AEE) and on the conditions of supply, understanding that universal access must be carried out with quality conditions. The analysis suggests a decrease in specialized educational assistance in partner institutions, which signals a different stance from what is observed in the country. Curitiba, has carried out the AEE in its own institutions, in its own schools or in Municipal Centers for Specialized Educational Service (CMAEE).

\footnotetext{
${ }^{1}$ Mestre em Educação. Universidade Federal do Paraná (UFPR). Curitiba, PR. Brasil. Orcid: https://orcid.org/0000-0002-1983-5708 e-mail: raphaeldemostenes@gmail.com.

${ }^{2}$ Doutora em Educação. Universidade Federal do Paraná (UFPR). Curitiba, PR. Brasil. Docente do PPGE da UFPR. Orcid: https://orcid.org/0000-0002-6346-2849 e-mail: gabrielaschneider@ufpr.br
} 
Keywords: Municipal Education Plan; Special education; Educational indicators;

\section{Introdução}

Este artigo tem como objetivo analisar o Plano Municipal de Educação - PME do município de Curitiba, através da criação de um sistema de indicadores que auxiliem na verificação no que tange especificamente a meta 4 , que se refere aos estudantes público-alvo da educação especial - PAEE. O PME da cidade de Curitiba foi instituído pela lei n ${ }^{\circ} 14.681$ de junho de 2015 (CURITIBA, 2015), tendo como documentos orientadores: o Plano Nacional de Educação - PNE (BRASIL, 2014), a Lei de Diretrizes e Bases da Educação Nacional - LDBN (BRASIL, 1996), os textos elaborados pelo Fórum Nacional de Educação - FNE, o documento Final da Conferência Nacional de Educação - CONAE (CONAE, 2014), as orientações do Ministério da Educação - MEC sobre a construção, adequação e alinhamento dos planos e a Política Nacional de Educação Especial na Perspectiva da Educação Inclusiva - PNEEPEI (BRASIL, 2008).

De cunho quantitativo, as informações aqui apresentadas, coletadas e tratadas (de forma secundária), são possíveis pela disponibilização dos microdados do Censo escolar e a aplicação de métodos quantitativos. Explica Richardson (1999), que a pesquisa quantitativa é caracterizada pelo emprego da quantificação, tanto nas modalidades de coleta de informações quanto no tratamento delas por meio de técnicas estatísticas.

Com 26 metas que tratam da educação infantil ao ensino superior, sua meta 4 trata de forma específica da educação inclusiva, que tem como público-alvo: educandos com deficiência, transtornos globais do desenvolvimento e altas habilidades ou superdotação. A universalização da educação básica e o atendimento educacional especializado, com a garantia de sistema educacional inclusivo, sob a administração pública ou conveniada, são as tônicas da meta (CURITIBA, 2015).

Fica evidente no PME do município de Curitiba, através do seu desdobramento em ações, objetivos e estratégias que se trata de um desenho de política pública, que tem convergência com outras leis que tratam da educação escolar em geral e destinada ao PAEE. 
A análise de uma política pública, aqui materializada por um PME, é algo complexo e controverso sendo necessário o estabelecimento de critérios para poder avaliar, se e porque uma política é preferível à outra, e o entendimento de que ela é fruto de debates e disputas desde sua elaboração até sua implementação (FIGUEIREDO; FIGUEIREDO, 2006).

Ressalte-se que um dos documentos norteadores para o PME é a PNEEPEI (Brasil, 2008), que orienta um conjunto de objetivos e ações para o exercício do Direito à educação para todos, sem discriminação e de forma inclusiva. Resta ao PME (CURITIBA, 2015) metade do tempo previsto para sua execução, considerando sua vigência de 10 anos que compreende o período do ano de 2015 a 2025, tornando seu acompanhamento necessário para indicar os avanços, estagnações e até retrocessos desta política educacional do município, proposto neste trabalho.

\section{O Plano Municipal de Educação de Curitiba e a Educação Especial na perspectiva inclusiva}

A política pública pode ser explicitada de várias formas (leis, programas, financiamentos) e o Plano de Educação, aqui analisado no âmbito municipal, é uma delas. Há um grande debate acerca do termo política pública, sendo aqui compreendido como: “[...] diretrizes, princípios norteadores de ação do poder público; regras e procedimentos para as relações entre poder público e sociedade, mediações entre atores da sociedade e do Estado." (TEIXEIRA, 2002, p. 02).

Porém, é necessário destacar que:

Nem sempre, porém, há compatibilidade entre as intervenções e declarações de vontade e as ações desenvolvidas. Devem ser consideradas também as "não-ações", as omissões, como formas de manifestação de políticas, pois representam opções e orientações dos que ocupam cargos. (Ibidem, p. 22, grifo nosso).

A Lei Orgânica do município de Curitiba, em seu capítulo três, trata do PME, e diz que: "Compete ao Município elaborar o Plano Municipal de Educação [...]" (CURTIBA, 1990, Art. 172). Suas 26 metas versam sobre: a educação infantil, o ensino fundamental, o ensino médio, a educação especial, a educação de jovens e adultos, a educação profissional, 
a educação superior, os trabalhadores da educação, a gestão democrática, o financiamento, o regime de colaboração, a educação e direitos humanos e a educação ambiental. Todos estes temas somam 326 estratégias que embasadas no PNE, conforme o artigo $4^{\circ}$, "as metas e estratégias, previstas no Anexo desta Lei, serão cumpridas no prazo de vigência do Plano Municipal de Educação do Município - PME, em estrita conformidade ao PNE” (CURITIBA, 2015 , art. $\left.4^{\circ}\right)$.

Entende-se então, que as metas e estratégias publicadas neste plano devem ser implementadas até o ano de 2025, sendo fundamental o acompanhamento pelo governo e pela sociedade civil de forma contínua.

Contudo, apesar da importância do exposto, a simples definição e inscrição em lei não garantem a sua efetivação, sendo necessárias ações políticas que façam com que as metas e estratégias sejam efetivadas. Além disso, o constante acompanhamento, avaliação e monitoramento são essenciais para compreender os desafios e redirecionar ações, afinal, como afirma Schneider (2014):

As políticas públicas enquanto quadros normativos de ação precisam ser constantemente avaliados a fim de se perceber se gerou um produto físico e/ou impactos, sejam eles subjetivos/objetivos como apontam Figueiredo e Figueiredo (1986). Além disso, é necessário avaliar uma política pública para poder repensá-la e mesmo prestar conta à sociedade civil da materialização (ou não) do seu direito (ibidem, p. 230, grifo nosso).

$\mathrm{Na}$ contramão dos apontamentos da pesquisadora Schneider (2014) e do PNE (BRASIL, 2014) em seu artigo quinto, o PME (CURITIBA, 2015) não especifica a responsabilidade do monitoramento e avaliação de suas metas e estratégias, também, não especifica a responsabilidade da periodicidade à sua publicização, o que reforça a necessidade de acompanhamento pelos agentes sociais. Enquanto o PNE (BRASIL, 2014) está em seu terceiro relatório de monitoramento, que é feito bianualmente pelo Instituto Nacional de Estudos e Pesquisas Anísio Teixeira - INEP, o PME curitibano está sem acompanhamento publicizado nos meios oficiais e sem a definição dos responsáveis à realização dessa ação.

No referido plano municipal a educação inclusiva é elencada como dever 
constitucional do Estado e da família sendo sua oferta em instituições de ensino comum e instituições de educação com ensino na modalidade de educação especial. A oferta pode se dar em classes especiais quando os estudantes PAEE não apresentarem condições de aprendizagem nas classes comuns, e, além disso, com a garantia do atendimento educacional especializado - AEE (CONSELHO MUNICIPAL DE EDUCAÇÃO, 2015). Tal qual ocorre no Plano Nacional de Educação, essa modalidade educacional também está prevista na meta número 4 do PME, e conta com 27 estratégias especificas, porém, além delas, há sinalização de uma perspectiva inclusiva que aparece em diversas outras estratégias relacionadas a outras etapas e modalidades.

Dentre as estratégias, temos como exemplos a 1.13, 2.8, 2.13, 2.30, 2.37, 3.9, 3.16, $4.9,4.10,4.12,4.25,4.26,5.12,6.4,6.13,7.5,7.10,7.25,8.8,9.16,10.4,11.9,12.3,12.4$, 13.1, 15.9, 16.5, 19.2, 23.9, 24.6. Essas exemplificam o entendimento que a modalidade da educação especial está idealizada e inscrita de forma a perpassar todos os níveis de ensino, de maneira colaborativa, junto aos demais entes federativos, conforme preconizado pela LDB (BRASIL, 1996), Lei Brasileira de Inclusão - LBI (BRASIL, 2015), PNEEPEI (BRASIL, 2008) e PNE (BRASIL, 2014).

Também, se reconhece no documento a necessidade do $\mathrm{AEE}^{3}$, atendendo a demandas como: a educação bilíngue para surdos, o fortalecimento dos centros de atendimento especializados, o incentivo a pesquisas, formação, aplicação e manutenção de tecnologias educacionais, a profissionalização das pessoas com deficiência, a adequação arquitetônica, transporte acessível, material didático acessível, etc.

De acordo com o Ministério Público Federal - MPF (2004), é necessário que alguns recursos estejam disponíveis nas escolas de ensino comum, para que elas possam atender com qualidade aos alunos com e sem deficiência. O que reforça o entendimento de que o

\footnotetext{
${ }^{3}$ O AEE é um serviço específico da educação especial que organiza atividades, recursos pedagógicos e de acessibilidade, de forma a complementar ou suplementar a escolarização dos alunos com deficiência, Transtorno do Espectro Autista (TEA) e/ou altas habilidades/superdotação matriculados nas classes comuns do ensino regular, com o objetivo de garantir condições de acesso, participação e aprendizagem. Esse serviço, instituído no projeto político-pedagógico da escola, é realizado preferencialmente na sala de recursos multifuncionais, individualmente ou em pequenos grupos, em horário distinto ao da escolarização em sala de aula comum. (INEP, 2019, p.46)
} 
PME -2015 aprovado, converge na busca de uma oferta inclusiva e de qualidade.

Cabe destacar que nas estratégias, a oferta do AEE aparece como um eixo central, sendo a oferta permitida por instituições convencionais, filantrópicas, comunitárias sem fins lucrativos que ofertem atendimento complementar e suplementar, que se fazem fortemente presentes na oferta educacional para os estudantes PAEE. Como alertam Oliveira e Célio Sobrinho (2020, p. 03), “emerge assim a ênfase, que permanece até os dias atuais, da necessidade de um caráter fortemente protetivo para esse público”.

Os autores ainda comentam que a utilização da esfera privada é uma forma de precarização do trabalho docente e compromete a universalização do AEE, sendo importante a análise do papel do setor privado na oferta educacional na modalidade de educação especial.

Diante de tais questões, bem como visando compreender como tem se consolidado a meta 4 do PME curitibano, busca-se contribuir com o debate e propor formas de analisar a implementação desse documento no aspecto de uma educação inclusiva, tratada a seguir.

\section{Indicadores para o diagnóstico da meta 4 do PME no município de Curitiba}

Segundo Januzzi (2017), a democratização e avaliação das políticas sociais, aliadas aos avanços tecnológicos e à ampliação das fontes de informação, têm colaborado para o avanço na criação e utilização de indicadores sociais à avaliação social com vistas a auxiliar os governos no planejamento e redirecionamento das ações.

No caso de um Plano que tem como objetivo planejar as ações educacionais para os próximos 10 anos, o constante monitoramento das políticas é essencial, seja para pressionar sua implementação, seja para o redirecionamento das ações. Para Gatti (2004, p. 19) “a análise da política educacional não pode prescindir do confronto do que é declarado nos pressupostos e metas que as orientam, com os dados a respeito dos resultados alcançados $[\ldots]^{\prime}$.

Contudo, a produção de dados e indicadores nem sempre é simples, pois depende da disponibilização de dados e informações que nem sempre estão acessíveis. Além disso, é necessário compreender que tais levantamentos têm limites e que, por vezes, dados 
produzidos com as mesmas fontes podem apresentar resultados diferentes, tendo em vista as escolhas metodológicas e cruzamentos realizados. Afinal, "os indicadores apontam, indicam, aproximam, traduzem em termos operacionais as dimensões sociais de interesse definidas a partir de escolhas teóricas ou políticas realizadas anteriormente" (JANUZZI, 2005, p.137).

Januzzi (2017) afirma que existem diversas propriedades dos indicadores: confiabilidade, relevância, cobertura, sensibilidade, desagregabilidade, entre outros, as quais devem ser observadas na elaboração de um indicador. Sendo, muitas vezes, necessário optar por certas propriedades em detrimentos das outras, pois, por exemplo, um indicador com maior cobertura, talvez não seja o mais sensível.

Tais escolhas permeiam a proposta de elaboração de dados e indicadores para avaliar o atendimento do PAEE. No caso específico dessa meta, uma das formas de analisar a universalização seria comparar a matrícula da população PAEE e da população que apresenta alguma deficiência. Contudo, há limitações no que tange a escassez de dados sobre o PAEE nos Censos Demográficos que só são realizados de 10 em 10 anos, sendo que o último dado disponível é de $2010^{4}$. Além disso, a identificação de algumas dessas condições nem sempre é feita antes do acesso à escola. Portanto, é preciso pensar indicadores com dados e informações disponíveis. Pois, como bem explicitam Mendes e D'Affonseca (2018, p.935):

O aluno PAEE pode chegar à escola já identificado, o que provavelmente acontece a uma minoria de estudantes cujas condições são de alta visibilidade, como é o caso das deficiências sensoriais, físicas e determinadas síndromes, e por isso são identificadas pelo sistema de saúde ou mesmo pela própria família. Entretanto, a grande maioria de estudantes, particularmente aqueles com suspeita de deficiência intelectual, são identificados pela escola, incialmente por um professor do ensino comum.

No que tange a perspectiva adotada nesse artigo, entende-se que pensar o acesso e universalização implica mais do que pensar a garantia da vaga, mas precisa ser feito considerando o modo como se dá essa oferta, ou seja, as condições de oferta.

Estudos de Neto et al (2005), Dourado et al (2007) e Schneider e Gouveia (2011),

\footnotetext{
${ }^{4}$ O Censo Demográfico deveria ter sido realizado em 2020, contudo, por conta da pandemia de Covid-19 e cortes no orçamento, ainda não foi realizado.
} 
indicam algumas características que compõem a oferta escolar, tais como infraestrutura, formação docente e que podem ser considerados indicadores para auxiliar no diagnóstico do PME aqui estudado. Também, é necessário transpor para o município o acompanhamento que já é realizado pelo PNE (BRASIL, 2014), neste caso, considerando a realidade municipal.

Nesse sentido, com a utilização de dados do Censo Escolar (INEP, 2015; 2019) para análise da meta, considerando a disponibilidade dos dados inclusive em série histórica, se mensura o quantitativo dos estudantes que estão matriculados nas escolas e as características desta oferta. Sendo utilizado ferramentas computacionais e os dados quantitativos secundários, é construído o conjunto de indicadores descritos no quadro abaixo, como parâmetro para diagnosticar o PME (CURITIBA, 2015), na perspectiva da educação inclusiva.

Quadro 1 - Indicadores para diagnosticar o PME (CURITIBA, 2015)

\begin{tabular}{|c|c|c|}
\hline Indicador & Descrição e forma de cálculo & Censo Escolar \\
\hline $\begin{array}{c}\text { Existência de } \\
\begin{array}{c}\text { Sala de } \\
\text { Atendimento } \\
\text { especial }\end{array}\end{array}$ & Contagem das escolas que possuem sala de atendimento \\
especial. & Arquivo escola \\
\hline $\begin{array}{c}\text { Existência de } \\
\text { banheiro } \\
\text { adequado }\end{array}$ & Contagem das escolas que possuem banheiro adequado. & Arquivo escola \\
\hline $\begin{array}{c}\text { Existência de } \\
\text { vias e } \\
\text { dependências } \\
\text { acessíveis }\end{array}$ & Contagem das escolas possuem vias e dependências acessíveis. & Arquivo escola \\
\hline $\begin{array}{c}\text { Total de } \\
\text { Matrículas PAEE }\end{array}$ & $\begin{array}{c}\text { Contagem das matrículas dos alunos Público-alvo da educação } \\
\text { especial. }\end{array}$ & Arquivo matrícula \\
\hline $\begin{array}{c}\text { Total de } \\
\text { Matrículas AEE }\end{array}$ & $\begin{array}{c}\text { Contagem das matrículas dos alunos com PAEE que recebem o } \\
\text { AEE. }\end{array}$ & Arquivo matrícula \\
\hline $\begin{array}{c}\text { Percentual de } \\
\text { matrículas AEE } \\
\text { e Exclusivas }\end{array}$ & $\begin{array}{c}\text { Percentual de matrículas em classes exclusivas= (matrículas em } \\
\text { classes especiais ou escolas exclusivas ou aluno que recebe o } \\
\text { PAEE da educação básica de alunos PAEE)/(total de matrículas } \\
\text { da educação básica de alunos PAEE). }\end{array}$ & Arquivo matrícula \\
\hline
\end{tabular}

\footnotetext{
${ }^{5}$ Espaço localizado nas escolas de educação básica em que se realiza o atendimento educacional especializado. São constituídos por equipamentos, mobiliários, recursos de acessibilidade e materiais didático-pedagógicos para atender a escolas públicas com alunos da educação especial, matriculados em classe comum do ensino regular e registrados no Censo Escolar. As salas de recursos multifuncionais podem ser implementadas por meio de programa federal ou por recursos próprios dos sistemas de ensino. Além disso, o AEE deve ser realizado por professor com formação em educação especial (INEP, 2019, p. 25).

${ }^{6}$ Indicador com referência no $3^{\circ}$ Relatório de monitoramento do PNE (INEP, 2020, p.456).
} 


\begin{tabular}{|c|c|c|}
$\begin{array}{c}\text { Percentual de } \\
\text { matrículas } \\
\text { classes comuns }\end{array}$ & $\begin{array}{c}\text { Percentual de matrículas em classes comuns=(matrículas em } \\
\text { classes comuns da educação básica na de alunos PAEE)/(total } \\
\text { de matrículas da educação básica de alunos PAEE). }\end{array}$ & Arquivo matrícula \\
\hline
\end{tabular}

Fonte: Elaborado pelos autores com referência no PNE (2014) e variáveis disponibilizadas pelo Censo Escolar (INEP, 2014; 2019)

O indicador Total de Matrículas PAEE considera os estudantes classificados no Censo escolar (INEP, 2014; 2019) como matriculados em turmas, cujo tipo de turma não é de atividade complementar ou AEE. Já o Total de Matrículas AEE considera os estudantes identificados com esse atendimento.

A análise será feita considerando outras características da oferta, como por exemplo, a dependência administrativa da escola, buscando compreender se a oferta se amplia na rede pública, sendo desagregados em matrículas da rede municipal (federal, estadual e municipal) e matrículas conveniadas com o poder público (privadas). Considera-se o ano de 2015, primeiro ano do PME (CURITIBA, 2015) e 2019, que são os últimos dados disponíveis. A seguir, a análise dos indicadores do Quadro 1.

\section{Avaliação do PME de Curitiba na perspectiva da educação inclusiva}

Uma primeira análise a ser feita refere-se as matrículas do PAEE que, conforme mostra a Tabela 1 vem crescendo, o que pode sinalizar um aumento do acesso ou uma melhoria nos processos de identificação dessas matrículas ou mesmo uma melhoria nos procedimentos de registro e acompanhamento.

Se considerarmos as esferas públicas (federal, estadual e municipal) e privadas (conveniadas ou não e com ou sem fins lucrativos) que ofertam a educação básica é possível visualizar um panorama do número de matrículas de alunos PAEE em classes comuns e exclusivas no município na educação básica. Tem-se um avanço no número de matrículas, em ambas as esferas, sendo a esfera pública, maior responsável pela absorção de matrículas, aproximadamente quatro vezes maior do que a esfera privada.

\footnotetext{
${ }^{7}$ Indicador com referência no $3^{\circ}$ Relatório de monitoramento do PNE (INEP, 2020, p.459).
} 
Tabela 1- Matrículas de alunos PAEE no município de Curitiba em classes comuns e exclusivas nos anos de 2015 e 2019

\begin{tabular}{c|c|c|c|c|c|c}
\hline & \multicolumn{2}{|c|}{ Matrículas 2015 } & \multicolumn{2}{c|}{ Matrículas 2019 } & \multicolumn{2}{c}{$\Delta$} \\
(Matrículas 2015-2019)
\end{tabular}

Fonte: Elaborado pelos autores com referência na sinopse estatística do Censo Escolar fornecido pelo INEP (2015; 2019).

Esse panorama reforça a necessidade de observar a rede municipal e seu convênio com o poder público, conforme a meta 4 do PME (CURITIBA, 2015) especifica, e que corrobora com as observações do estudo de Oliveira e Sobrinho (2020) no território capixaba, que identificam a necessidade de maior transparência nos aspectos da sociodinâmica Público-Privado no estado do Espírito Santo.

Ainda que o PME curitibano seja pensado para toda a educação básica, opta-se por analisar apenas a rede municipal e conveniada, porque elas possibilitam compreender a atuação do município. Cabe destacar que, nesse caso, a análise versa mais especificamente sobre as escolas de educação infantil e anos iniciais do ensino fundamental (regular ou EJA) e algumas (poucas) matrículas de ensino fundamental anos finais ${ }^{8}$.

Ao verificar a quantidade total destas matrículas de alunos PAEE apenas nas redes municipais e conveniadas e que podem ou não receber o AEE, se evidencia o aumento de 14,94\% do número de matrículas no período. Observa-se também, que a rede municipal possui um maior crescimento absoluto no número de matrículas (1604 e 59), totalizando 1663 matrículas. O total do número de matrículas de alunos PAEE, nas escolas conveniadas, sofreu uma queda considerável de 39,95\% (173), entre 2015 e 2019.

Tabela 2- matrículas de alunos PAEE que recebem o AEE em escolas municipais e conveniadas,

\footnotetext{
${ }^{8}$ No estado do Paraná a divisão de responsabilidade pelo ensino fundamental entre estados e municípios é dada com os primeiros assumindo os anos finais e os segundos os anos iniciais. Em 2019, Curitiba tinha 5.868 matrículas de anos finais o que corresponde a 6,0\% do total de matrículas nessa fase, enquanto o estado contava com $66,4 \%$, a rede federal por 0,5 e a rede privada por $27,1 \%$.
} 


\section{REVISTA DE ADMINISTRAÇÃO EDUCACIONAL}

ISSN -2359-1382

Curitiba, $2015-2019$

\begin{tabular}{|c|c|c|c|c|c|c|c|c|}
\hline & \multicolumn{2}{|c|}{ Matrículas 2015} & \multicolumn{2}{|c|}{ Matrículas 2019} & \multicolumn{2}{|c|}{$\begin{array}{c}\Delta \\
\text { (Matrículas 2015-2019) }\end{array}$} & \multicolumn{2}{|c|}{$\begin{array}{c}\Delta \% \\
\text { (Matrículas 2015-2019) }\end{array}$} \\
\hline & PAEE & AEE & PAEE & AEE & PAEE & AEE & PAEE & AEE \\
\hline Municipal & 4000 & 1151 & 5604 & 1210 & 1604 & 59 & $40,10 \%$ & $5,13 \%$ \\
\hline Conveniada & 3215 & 433 & 3036 & 260 & -179 & -173 & $-5,57 \%$ & $-39,95 \%$ \\
\hline Total & 7215 & 1584 & 8640 & 1470 & 1425 & -114 & $19,75 \%$ & $-7,20 \%$ \\
\hline Total por ano & \multicolumn{2}{|c|}{8799} & \multicolumn{2}{|c|}{10110} & \multicolumn{2}{|c|}{1311} & \multicolumn{2}{|c|}{$14,90 \%$} \\
\hline
\end{tabular}

Fonte: Elaborado pelos autores com referência nos microdados do Censo Escolar fornecido pelo INEP

Notas:

(2015;2019).

1 - Inclui escolas com Classes Exclusivas (Escolas Exclusivamente Especializadas e/ou Classes Exclusivas de Ensino Regular e/ou Educação de Jovens e Adultos) que possuem alunos com algum tipo de deficiência, transtorno global do desenvolvimento ou altas habilidades/superdotação.

Cabe considerar que o AEE é um atendimento complementar ou suplementar sendo que não são todos os estudantes que necessitam desse tipo de serviço. Nesse sentido, o levantamento da demanda é complexo e exigiria uma análise por escola, para verificar a quantidade de estudantes que demandam atendimento e ainda não o possuem.

No que se refere ao total de matrículas das turmas ou classes exclusivas, também chamadas de classes especiais, a tabela abaixo mostra convergência com as informações acima, em que os alunos PAEE, tiveram acréscimo no número de matrículas nas escolas municipais. E nas escolas conveniadas, decréscimo no período. Porém, evidencia que grande parte das matrículas desses alunos na rede conveniada, está alocada em turmas exclusivas de alunos com deficiência.

Tabela 3- matrículas de alunos PAEE em classes ou turmas exclusivas em escolas municipais e conveniadas, Curitiba, $2015-2019$

\begin{tabular}{|c|c|c|c|c|}
\hline & Matrículas 2015 & Matrículas 2019 & \begin{tabular}{|c|}
$\Delta$ \\
(Matrículas 2015-2019)
\end{tabular} & $\begin{array}{c}\Delta \% \\
\text { (Matrículas 2015-2019) }\end{array}$ \\
\hline Municipal & 1528 & 1747 & 219 & $14,33 \%$ \\
\hline Conveniada & 3189 & 2945 & -244 & $-7,65 \%$ \\
\hline
\end{tabular}

Fonte: Elaborado pelos autores com referência nos microdados do Censo Escolar fornecido pelo INEP

(2015;2019).

Destacamos que:

[...] a ampliação da oferta do AEE na rede pública é a ação mais sensata, pois tem a alçada de materializar o preceito constitucional de educação 
com qualidade para todos, rechaçando qualquer mecanismo que venha a diminuir o escopo educacional que traga à tona preceitos já ultrapassados, tais como provisoriedade, excepcionalidade, segregação ou exclusão (OLIVEIRA; SOBRINHO, 2020, p. 06).

As matrículas de conveniamento com o poder público, as privadas estão estratificadas na tabela a seguir, mostrando que, entre os anos de 2015 e 2019, mais que dobraram o número de matrículas em instituições com fins lucrativos, também uma queda de 26,34\% no número de matrículas em instituições sem fins lucrativos. Evidenciando uma tendência de privatização para instituições com fins lucrativos, o que, inclusive é contraditório quando se considera as orientações para a realização de convênio, que não deveriam ser feitas com instituição com fins lucrativos.

Tabela 4 - número de matrículas PAEE conveniadas com a rede municipal com e sem fins lucrativos.

\begin{tabular}{c|c|c|c|c}
\hline Tipo de convênio & $\mathbf{2 0 1 5}$ & $\mathbf{2 0 1 9}$ & $\boldsymbol{\Delta}$ & $\begin{array}{c}\Delta \% \\
(\mathbf{2 0 1 5}-\mathbf{2 0 1 9})\end{array}$ \\
\hline (2015-2019) \\
\hline Conveniada com fins lucrativos & 452 & 929 & 477 & $105,53 \%$ \\
Conveniada sem fins lucrativos & 2737 & 2016 & -721 & $-26,34 \%$ \\
Total & 3189 & 2945 & -244 & $-7,65 \%$ \\
\hline
\end{tabular}

Fonte: Elaborado pelos autores com referência nos microdados do Censo Escolar fornecido pelo INEP (2015;2019).

Garantir a universalização do atendimento, bem como a ampliação do acesso ao AEE exige mais do que uma vaga, mas, condições efetivas capazes de garantir o pleno desenvolvimento da pessoa. A questão da infraestrutura, apesar de não estar diretamente relacionada a meta, auxilia a compreensão do modo como a meta está sendo cumprida. No caso em questão, com base nos dados do censo escolar é possível analisar a existência nas escolas de sala de AEE, banheiro adequado e vias e dependências acessíveis.

Essas características compõem parte da infraestrutura da escola e os autores Oliveira e Araújo (2005), Ximenes (2014) e Schneider e Gouveia (2011) convergem ao elencar a infraestrutura como um dos elementos que compõem o direito à educação de qualidade que pressupõem o acesso e permanência do PAEE, com autonomia e segurança.

As escolas foram selecionadas considerando sua situação de funcionamento (escolas em atividade), sua dependência administrativa (escolas da rede municipal e conveniadas com 
o poder público) e que tenham pelo menos uma matrícula de ensino regular, educação de jovens e adultos (EJA), educação profissional e/ou uma turma exclusiva de alunos com deficiência, transtorno global do desenvolvimento ou altas habilidades/superdotação.

O município de Curitiba possuía 383 escolas da rede municipal e 117 escolas conveniadas em 2015. Em 2019, o total municipal aumentou para 415 escolas municipais e 115 escolas conveniadas, um aumento de 32 escolas da rede municipal e redução de duas escolas conveniadas.

Tabela 5- número de escolas da rede municipal e conveniadas com o município

\begin{tabular}{c|c|c|c}
\hline & $\mathbf{2 0 1 5}$ & $\mathbf{2 0 1 9}$ & $\boldsymbol{\Delta}$ \\
& & $\mathbf{2 0 1 5 - 2 0 1 9 )}$ \\
\hline Municipal & 383 & 415 & 32 \\
Conveniada & 117 & 115 & -2 \\
Total & 500 & 530 & 30 \\
\hline
\end{tabular}

Fonte: Elaborado pelos autores com referência nos microdados do Censo Escolar fornecido pelo INEP (2015; 2019).

Notas:

1 - Inclui escolas que ofertam Atendimento Educacional Especializado (AEE).

2 - Inclui escolas com Classes Exclusivas (Escolas Exclusivamente Especializadas e/ou Classes Exclusivas de Ensino Regular e/ou Educação de Jovens e Adultos) que possuem alunos com algum tipo de deficiência, transtorno global do desenvolvimento ou altas habilidades/superdotação.

Esse aumento no número de escolas indica a criação de novos prédios escolares, mas também, se deve ao AEE. Ao considerar o AEE no tratamento dos dados, é possível identificar que o município do ano de 2015, para 2019 teve um aumento de 9 (nove) escolas com a oferta exclusiva do AEE na rede municipal, que se refere aos 9 (nove) Centros Municipais de Atendimento Educacional Especializado - CMAEE. Também a redução de duas escolas que ofertavam de forma não exclusiva o AEE. Segundo a Secretaria Municipal de Educação:

O Centro Municipal de Atendimento Educacional Especializado (CMAEE) oferta avaliação diagnóstica psicoeducacional e atendimento terapêuticoeducacional nas áreas de Pedagogia Especializada, Reeducação Auditiva, Reeducação Visual, Psicologia, Fonoaudiologia, Fisioterapia e Serviço Social a educandos PAEE, matriculados prioritariamente em escolas e creches Municipais ou residentes em sua área de abrangência, com vistas ao desenvolvimento de suas potencialidades e o resgate de melhores 
condições de desempenho pessoal, escolar e social. (SECRETARIA MUNICIPAL DE EDUCAÇÃO DE CURITIBA, 2020, n.p).

Na tabela abaixo é possível verificar o tipo de oferta de AEE ofertado em instituições municipais e conveniadas.

Tabela 6- Tipo da oferta do AEE em escolas municipais e conveniadas, Curitiba, 2015 e 2019

\begin{tabular}{c|c|c|c|c}
\hline \multirow{2}{*}{} & \multicolumn{2}{|c|}{2015} & \multicolumn{2}{c}{2019} \\
\cline { 2 - 5 } & Municipal & Conveniada & Municipal & Conveniada \\
\hline Exclusivamente & 0 & 7 & 9 & 4 \\
Não exclusivamente & 71 & 8 & 69 & 7 \\
Não oferta & 312 & 102 & 337 & 104 \\
Total & 383 & 117 & 415 & 115 \\
\hline
\end{tabular}

Fonte: Elaborado pelos autores com referência nos microdados do Censo Escolar e fornecido pelo INEP (2015; 2019).

Dentre os nove CMAEE, cabe o destaque para o primeiro Centro de Ensino Estruturado para o Transtorno do Espectro Autista (TEA) do país, que auxilia na inclusão de alunos no sistema escolar, considerando as especificidades de cada indivíduo e por consequência, no alcance da meta quatro do PME (CURITIBA, 2015).

Todas as escolas (aqui nos referimos as que ofertam o ensino regular em classe comum e/ou exclusiva, com e/ou sem AEE) devem ser acessíveis para todos, e os indicadores como: existência de sala de atendimento especial, existência de banheiro adequado e existência de vias e dependências acessíveis, contribuem com essa perspectiva. Frise-se que a garantia da oferta de uma educação inclusiva está na estratégia 4.12 do PME (CURITIBA, 2015).

Abaixo a Tabela 7, contempla os indicadores referentes à acessibilidade arquitetônica da escola. Conforme explica Gatti (2004), temos aqui um exemplo das limitações dos dados quantitativos, pois a existência destes três indicadores propostos não garante a qualidade dos espaços. Por exemplo: a existência de banheiro adequado, não garante a existência de barras de apoio, manopla do tipo alavanca, exigidos pela norma técnica NBR 9050 (ABNT, 2015), inclusive, citada nos cadernos de instruções de 
preenchimento do Censo escolar, nos dois anos. A existência de dependências e vias acessíveis, não garantem que todas as portas sejam de tamanho adequado, ou que o piso de toda a escola seja regular, também preconizado na NBR 9050 (ABNT, 2015). Contudo, permitem indicar condições observadas e consideradas de acessibilidade pela escola respondente do Censo escolar.

No ano de 2015, havia no Censo escolar (INEP, 2015) uma única variável para tratar das condições de acessibilidade arquitetônica. Essa variável foi descontinuada no ano de 2019 e desmembrada na existência ou não de: corrimão e guarda corpos, elevador, pisos táteis, portas com vão livre de no mínimo $80 \mathrm{~cm}$, rampas, sinalização sonora, sinalização tátil (piso/paredes), e sinalização visual (piso/paredes).

Essa mudança justifica o déficit ao comparar na tabela abaixo, ao indicador de dependências e vias acessíveis nos anos de 2015 e 2019. Com a redução de 67 escolas municipais e 21 conveniadas.

Tabela 7 - escolas com sala de atendimento especial, banheiro adequado e dependências e vias acessíveis

\begin{tabular}{|c|c|c|c|c|c|c|c|c|c|c|}
\hline & \multicolumn{4}{|c|}{2015} & \multicolumn{4}{|c|}{2019} & \multicolumn{2}{|c|}{\begin{tabular}{|c|}
$\Delta$ \\
(Matrículas 2015-2019)
\end{tabular}} \\
\hline & \multicolumn{2}{|c|}{ Municipal } & \multicolumn{2}{|c|}{ Conveniada } & \multicolumn{2}{|c|}{ Municipal } & \multicolumn{2}{|c|}{ Conveniada } & Municipal & Conveniada \\
\hline Total de escolas & \multicolumn{2}{|c|}{383} & \multicolumn{2}{|c|}{117} & \multicolumn{2}{|c|}{415} & \multicolumn{2}{|c|}{115} & 32 & -2 \\
\hline $\begin{array}{l}\text { Existência de sala de } \\
\text { atendimento especial }\end{array}$ & 73 & $19,10 \%$ & 8 & $6,84 \%$ & 80 & $19,28 \%$ & 9 & $7,80 \%$ & 7 & 1 \\
\hline $\begin{array}{l}\text { Existência de sala de banheiro } \\
\text { adequado }\end{array}$ & 195 & $50,90 \%$ & 64 & $54,70 \%$ & 236 & $56,87 \%$ & 78 & $67,80 \%$ & 41 & 14 \\
\hline $\begin{array}{l}\text { Existência de vias e } \\
\text { dependencias acessíveis }\end{array}$ & 132 & $34,50 \%$ & 49 & $41,88 \%$ & 65 & $15,66 \%$ & 28 & $24,30 \%$ & -67 & -21 \\
\hline
\end{tabular}

Fonte: Elaborado pelos autores com referência nos microdados do Censo Escolar fornecido pelo INEP (2015;

2019).

A adaptação dos banheiros, representa tanto nas escolas municipais como nas conveniadas, um maior crescimento nesses 4 (quatro) anos. Porém, longe de poder afirmar com esse crescimento médio, que nos próximos anos todas as escolas irão ofertar um banheiro adequado para os alunos PAEE. De outra quadra, as salas de atendimento especial tiveram um menor crescimento, nesses anos.

$\mathrm{O}$ retrato dos indicadores acima, não contribuem à realização da meta 4 (quatro) do PME (CURITIBA, 2015), pois a universalização do acesso à escola passa pela 
adaptação dos espaços para todos.

Há muito a caminhar para que todas as escolas do município tenham salas para atendimento especial, dependências e vias acessíveis e banheiro adaptado. O crescimento médio no período analisado nas escolas municipais está longe de atingir 100\% de atendimento, assim como, em escolas conveniadas. Cabe a observação que as escolas conveniadas são contratadas pelo município e tais aspectos deveriam ser considerados no contrato destes convênios, ou, colocado como exigências de adequação, à aprovação de projetos e transferência de recursos.

Os dois últimos indicadores são uma transposição dos indicadores $4 \mathrm{~b}$ e $4 \mathrm{c}$ do $3^{\circ}$ relatório de monitoramento do PNE $-2014^{9}$ (INEP, 2020). Os dados municipais foram inseridos nas fórmulas de cálculo do Quadro 1, tendo como resultado:

Tabela 8- Percentual de matrículas de alunos PAEE em classe comum que recebem o AEE em escolas municipais e conveniadas

\begin{tabular}{|c|c|c|c|c|c|c|}
\hline & \multicolumn{2}{|c|}{2015} & \multicolumn{2}{|c|}{2019} & \multicolumn{2}{|c|}{$\begin{array}{c}\Delta \% \\
\text { (Matrículas 2015-2019) }\end{array}$} \\
\hline Municipal & $48,52 \%$ & $63,14 \%$ & $40,96 \%$ & $70,86 \%$ & $-7,56 \%$ & $7,72 \%$ \\
\hline Conveniada & $94,86 \%$ & $0,70 \%$ & $92,85 \%$ & $6,73 \%$ & $-2,01 \%$ & $6,03 \%$ \\
\hline
\end{tabular}

Fonte: Elaborado pelos autores com referência nos microdados do Censo Escolar e fornecido pelo INEP (2015;2019).

O percentual de matrículas de alunos PAEE em classes comuns teve crescimento nas redes municipais e conveniadas $(+7,72 \% \mathrm{e}+6,03 \%)$. No que se refere a matrícula de alunos do PAEE que recebem o AEE (em classes especiais ou escolas exclusivas) na faixa etária de obrigatoriedade houve leve queda nos pontos percentuais dos indicadores $(+7,56 \%$ e $2,01 \%)$.

Destaca-se o alto percentual desses alunos nas escolas conveniadas $(94,86 \%$ e 92,85\%) mostrando certa estabilidade no período, e a tendência a transferência dos alunos PAEE que necessitam do AEE para a rede conveniada, indo em direção oposta a estratégia 4.12, por exemplo, que é a garantia de uma educação inclusiva.

\footnotetext{
${ }^{9}$ Há ausência de dados demográficos para o cálculo do indicador 4a, do relatório de monitoramento do PNE (2014) aplicado ao município de Curitiba.
} 
Sendo o município responsável por matrículas de 0 a 4 anos, foi construído o indicador acima desconsiderando a idade, para avaliar se há um grande impacto além da idade de obrigatoriedade (4 a 17 anos).

Tabela 9- Percentual de matrículas de alunos PAEE em classe comum e que recebem o AEE em escolas municipais e conveniadas

\begin{tabular}{c|c|c|c|c|c|c|}
\hline \multirow{2}{*}{} & \multicolumn{2}{|c|}{2015} & \multicolumn{2}{c|}{2019} & \multicolumn{2}{c|}{$\begin{array}{c}\Delta \% \\
\text { (Matrículas 2015-2019) }\end{array}$} \\
\cline { 2 - 6 } & $\begin{array}{c}\text { Percentual de } \\
\text { matrículas AEE e } \\
\text { Exclusivas }\end{array}$ & $\begin{array}{c}\text { Percentual de } \\
\text { matrículas em classes } \\
\text { comuns }\end{array}$ & $\begin{array}{c}\text { Percentual de } \\
\text { matrículas AEE e } \\
\text { Exclusivas }\end{array}$ & $\begin{array}{c}\text { Percentual de } \\
\text { matrículas em } \\
\text { classes comuns }\end{array}$ & $\begin{array}{c}\text { Percentual de } \\
\text { matrículas AEE e } \\
\text { Exclusivas }\end{array}$ & $\begin{array}{c}\text { Percentual de } \\
\text { matrículas em } \\
\text { classes comuns }\end{array}$ \\
\hline Municipal & $38,20 \%$ & $61,80 \%$ & $31,17 \%$ & $68,82 \%$ & $-7,03 \%$ & $-2,19 \%$ \\
Conveniada & $99,19 \%$ & $0,81 \%$ & $97 \%$ & $2,99 \%$ & $2,02 \%$ \\
\hline
\end{tabular}

Fonte: Elaborado pelos autores com referência nos microdados do Censo Escolar e fornecido pelo INEP (2015;2019).

As tendências convergem no que se referem ao aumento do percentual de matrículas em classes comuns e redução do percentual de matrículas do AEE de 2015 para 2019, nas escolas municipais e conveniadas. Como já explicitado anteriormente, a necessidade do AEE não se dá para todos os estudantes, contudo, deveria haver vagas para todos que precisam, porém, essa avaliação não pode ser feita com os dados disponíveis. Por outro lado, o aumento de estudantes PAEE em escolas regulares de ensino comum, especialmente na rede pública, indica o fortalecimento de uma política de educação inclusiva, que pode estar ameaçada diante de prerrogativas do novo decreto para a educação especial.

\section{Considerações finais}

O PME (CURITIBA, 2015) possui diversas frentes de trabalho para que se alcance a universalização do acesso de estudantes PAEE em idade obrigatória de frequência ao sistema escolar. A perspectiva inclusiva, as salas de recursos, classes exclusivas, escolas exclusivas e CMAEs são estruturas para que seja efetivada a garantia desse direito e a evolução para que ocorra o cumprimento da meta e estratégias. Ao mesmo tempo, observar questões específicas, auxiliam a identificar que esse PME precisa que seja definido responsáveis para seu acompanhamento, também definir indicadores como os propostos aqui para que sejam periodicamente acompanhados.

O PME apresenta uma perspectiva inclusiva em várias etapas e considera muitos 
pontos da política educacional vigente, reforçando a necessidade de acompanhamento de forma sistêmica, a transparência e a disponibilização dos dados.

Por fim, houve avanços, mas preocupam questões evidenciadas nos indicadores, como: o ínfimo crescimento das condições materiais e estruturais da escola (sala de recursos, banheiro, banheiro adaptado e dependências e vias acessíveis), a falta de dados que impedem à aferição da meta (população com deficiência, altas habilidades/superdotação e TEA fora da escola), o atendimento especializado privatizado em instituições com fins lucrativos, a falta de acompanhamento do Plano por organizações da sociedade civil e a falta de indicadores que retratem a realidade do município de Curitiba.

Por outro lado, é interessante observar o crescimento do atendimento educacional especializado na rede pública e o, ainda que pequeno, aumento de estudantes em escolas regulares de ensino comum. Outros estudos e pesquisas precisam ser realizados para elucidar outros aspectos, além da comparação dos dados com outros estados e municípios brasileiros.

\section{REFERÊNCIAS}

ADRIÃO, T. Dimensões e formas da privatização da educação no Brasil: Caracterização a partir de mapeamento de produções nacionais e internacionais. Currículo sem Fronteiras, v. 18, n. 1, p. 8-28, 2018.

BRASIL. Instituto Nacional de Estudos e Pesquisas Educacionais Anísio Teixeira (Inep). Microdados para download: microdados Censo Escolar (2015-2019). Brasília, DF, [s.d.].

.Orientações de preenchimento do Censo Escolar 2015: programas e políticas federais. Brasília, DF: Inep, 2017.

Constituição da República Federativa do Brasil de 1988. Brasília, DF, Presidência da República, 1988.

Lei no 9.394, de 20 de dezembro de 1996. LDB. Estabelece as diretrizes e bases da educação. DF, Brasil, 1996.

Lei $n^{\circ}$ 13.005, de 25 de julho de 2014. Aprova o Plano Nacional de Educação - PNE e da outras providências. DF, Brasil, 2014.

CONSELHO MUNICIPAL DE EDUCAÇÃO. Deliberação CME n. 1/2015. Normas e 
Princípios para a Educação Especial nas etapas de educação infantil e do ensino fundamental, na modalidade de educação de jovens e adultos, nos programas de educação especial para o trabalho, para educandos com deficiências, transtornos globais do desenvolvimento, altas habilidades/superdotação, entendidas como necessidades educacionais especiais e/ou as específicas, do Sistema Municipal de Curitiba - SISMEN. Curitiba, 2015. Disponível em: https://mideducacao.curitiba.pr.gov.br/2015/9/pdf/00081932.pdf. Acesso em 21 set. 2020.

CURITIBA. Plano Municipal de Educação de Curitiba - PR (2015 a 2025). Lei Municipal no 14.681 de 2015. Curitiba, Brasil, 2015.

DOURADO, L. F.; OLIVEIRA, J. F.; SANTOS, C. A. A qualidade da educação: conceitos e definições. Inep, 2007. Disponível em: $<$ http://escoladegestores.mec.gov.br/site/8-biblioteca/pdf/qualidade_da_educacao.pdf $>$. Acesso em: 10 dez. 2020.

FIGUEIREDO, M. F. FIGUEIREDO, A. M. C. Avaliação política e avaliação de políticas: um quadro de referência teórica. Análise \& Conjuntura. Belo Horizonte, 1(3), p. 107127, set/dez, 2006.

GATTI, Bernardete A. Estudos quantitativos em educação. Educ. Pesquisa. São Paulo, v. 30, n. 1, p. 11-30, Apr. 2004.

INEP. Censo escolar da educação básica. Brasília: INEP, 2015. Disponível em: www.inep.gov.br. Acesso em: 10 dez. 2020

. Censo escolar da educação básica. Brasília: INEP, 2019. Disponível em: www.inep.gov.br. Acesso em: 10 dez. 2020

JANNUZZI, Paulo de Martino. Indicadores para diagnóstico, monitoramento e avaliação de programas sociais no Brasil. Revista do Serviço Público. Brasília 56 (2): 137-160 Abr/Jun 2005.

Indicadores sociais no Brasil. Campinas: Editora Alínea, 2017.

MENDES, E. G.; D' AFFONSECA, S. M. Avaliação dos estudantes público-alvo da educação especial: perspectiva dos professores especializados. Revista Educação Especial. Santa Maria, v. 31, n. 63, p. 923-938, out./dez. 2018. Disponível em: https://periodicos.ufsm.br/educacaoespecial/article/view/33082/pdf. Acesso em 05 Jan. 2021.

MINISTÉRIO PÚBLICO FEDERAL. O Acesso de Alunos com Deficiência às Escolas e Classes Comuns da Rede Regular. $2^{a}$ ed. rev. e atualiz. Brasília, Procuradoria Federal dos Direitos do Cidadão, 2004. 
NETO, J. J. S.; JESUS, G. R. DE.; KARINO, C. A.; ANDRADE, D. F. DE. Uma escala para medir a infraestrutura escolar. Estudos em Avaliação Educacional, v. 24, n. 54, p. 78-99, 2013. Disponível em: <http://educa.fcc.org.br/pdf/eae/v24n54/v24n54a05.pdf>. Acesso em: 10 dez. 2020

OLIVEIRA, R. P. DE; ARAUJO, G. C. DE. Qualidade do ensino: uma nova dimensão da luta pelo direito à educação. Revista Brasileira de Educação, n. 28, p. 5-23, 2005.

OLIVEIRA, G. M. de; CÉLIO SOBRINHO, R. Aspectos da Sociodinâmica Público e Privado na Política de Educação Especial no Estado do Espírito Santo. Revista de Financiamento da Educação, Porto Alegre, v. 10, n. 4, 2020. Disponível em: ttp://seer.ufrgs.br/fineduca. Acesso em: 10 dez. 2020

RICHARDSON, R. J. Pesquisa social: métodos e técnicas. São Paulo: Atlas, 334 p. 1999.

SCHNEIDER, G.; GOUVEIA, A. B. Qualidade de escola: uma proposta de índice para as condições materiais de escolas a partir de dados contextuais do Saeb. Revista Brasileira de Pós-graduação, Brasília, v. 8, n. supl.1, p 59-82, 2011. Disponível em: $<$ http://ojs.rbpg.capes.gov.br/index.php/rbpg/article/view/236/226>. Acesso em: $10 \mathrm{dez}$. 2020 .

SECRETARIA MUNICIPAL DE EDUCAÇÃO DE CURITIBA. Centro Municipal de Atendimento Educacional Especializado. Curitiba, 2020. Disponível em: https://educacao.curitiba.pr.gov.br/conteudo/centro-municipal-de-atendimentoeducacional-especializado-cmaee/5807. Acesso em: 10 dez. 2020.

SOUZA, Celina. Políticas públicas: questões temáticas e de pesquisa. Caderno CRH, Salvador, n. 39, jul./dez. 2003.

TEIXEIRA, E. C. O papel das políticas públicas no desenvolvimento local e na transformação da realidade. Revista AATR, Salvador, 2002. Disponível em: http://dhnet.org.br/dados/cursos/aatr2/a pdf/03_aatr_pp_papel.pdf. Acesso em: 24 jul. 2021.

Recebido em: 10/05/2021

Revisado em: 20/07/2021

Aceito em: 24/09/2021 